\title{
Publish and Flourish A Practical Guide for Effective Scientific Writing
}

\section{Amar A Sholapurkar}

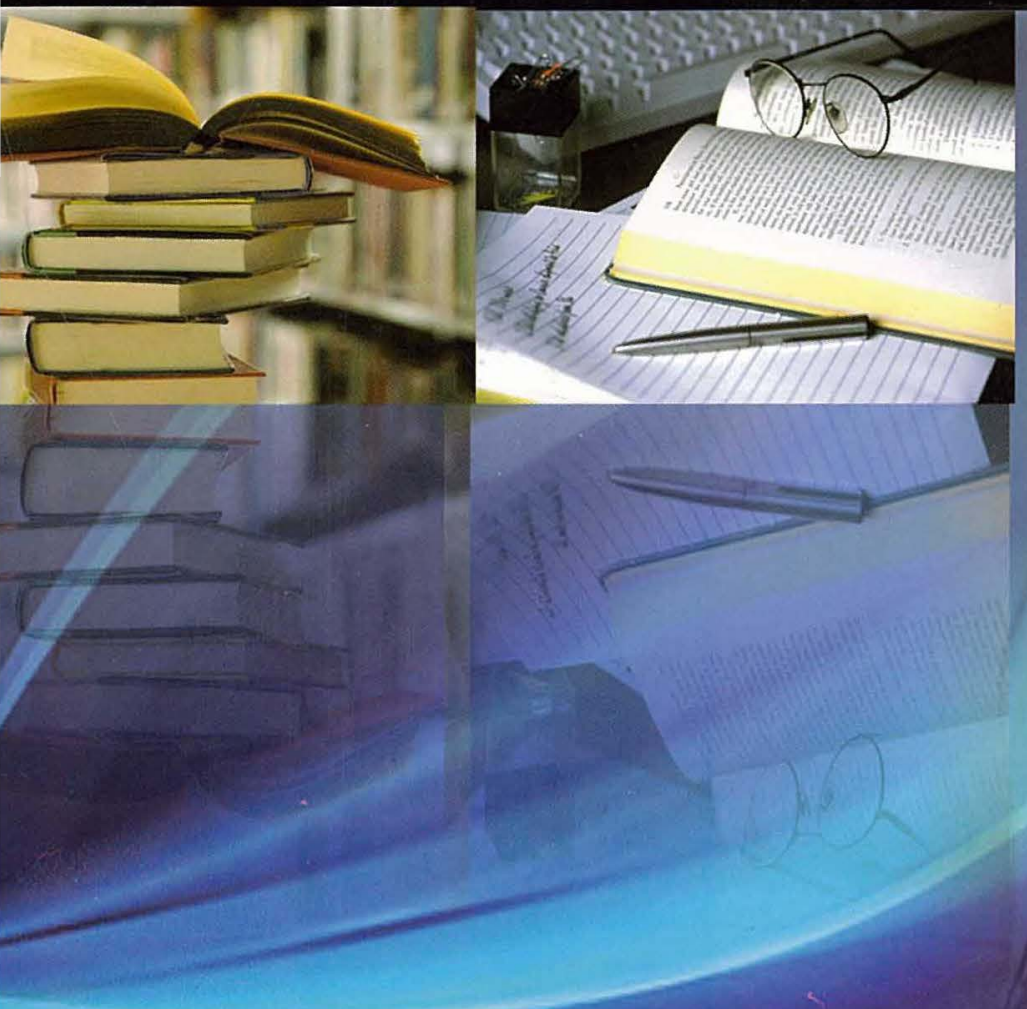

808.0665

PUB

C.A

K Ramnarayan

Shobha Tandon

JAYPEE 


\section{Also available...}

\section{Research Methodology Simplified} Every Clinician a Researcher

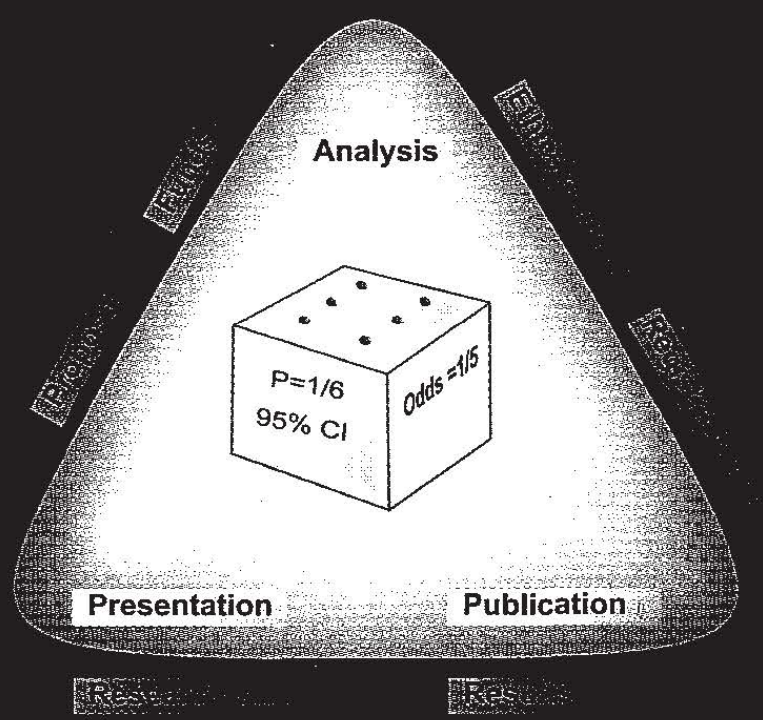

Mahendra N Parikh Avijit Hazra Joydev Mukherjee Nithya Gogtay

Forewords

PC Mahapatra

Mrudula Phadke

JAYPEE

Research Methodology Simplified Every Clinician a Researcher

Mahendra N Parikh, Avijit Hazra Joydev Mukherjee, Nithya Gogtay

$$
276 \text { Pages }
$$

ISBN 978-93-5025-003-7 


\section{Publish and Flourish A Practical Guide for Effective Scientific Writing}





\title{
Publish and Flourish \\ A Practical Guide for Effective Scientific Writing
}

\author{
Editor \\ Amar A Sholapurkar BDS MDS FAGE \\ Reader \\ Department of Oral Medicine and Radiology \\ Manipal College of Dental Sciences \\ Manipal, Karnataka, India
}

\author{
Forewords \\ Prof K Ramnarayan \\ Prof Shobha Tandon
}

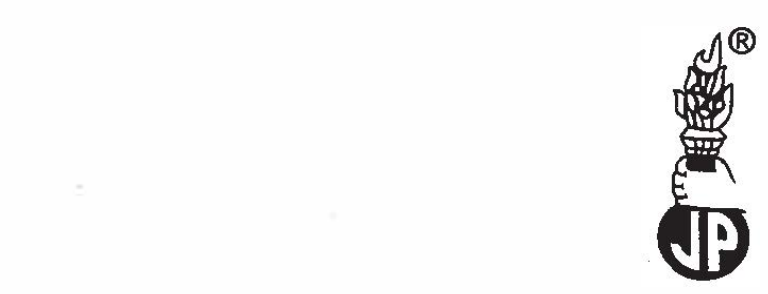

JAYPEE BROTHERS MEDICAL PUBLISHERS (P) LTD

New Delhi • Panama City • London 
Published by

Jaypee Brothers Medical Publishers (P) Ltd

Corporate Office

4838/24 Ansari Road, Daryaganj, New Delhi - 110002, India

Phone: +91-11-43574357, Fax: +91-11-43574314

Website: www.jaypeebrothers.com

\section{Offices in India}

- Ahmedabad, e-mail: ahmedabad@jaypeebrothers.com

- Bengaluru, e-mail: bangalore@jaypeebrothers.com

- Chennai, e-mail: chennai@jaypeebrothers.com

- Delhi, e-mail: jaypee @jaypeebrothers.com

- Hyderabad, e-mail: hyderabad@jaypeebrothers.com

- Kochi, e-mail: kochi@jaypeebrothers.com

- Kolkata, e-mail: kolkata@jaypeebrothers.com

- Lucknow, e-mail: lucknow@jaypeebrothers.com

- Mumbai, e-mail: mumbai@jaypeebrothers.com

- Nagpur, e-mail: nagpur@jaypeebrothers.com

\section{Overseas Offices}

- Central America Office, Panama City, Panama, Ph: 001-507-317-0160 e-mail: cservice@jphmedical.com, Website: www.jphmedical.com

- Europe Office, UK, Ph: +44 (0) 2031708910 e-mail: info@jpmedpub.com

\section{Publish and Flourish: A Practical Guide for Effective Scientific Writing}

(C) 2011, Jaypee Brothers Medical Publishers

All rights reserved. No part of this publication should be reproduced, stored in a retrieval system, or transmitted in any form or by any means: electronic, mechanical, photocopying, recording or otherwise, without the prior written permission of the editor and the publisher.

This book has been published in good faith that the material provided by the contributors is original. Every effort is made to ensure accuracy of material, but the publisher, printer and editor will not be held responsible for any inadvertent error (s). In case of any dispute, all legal matters are to be settled under Delhi jurisdiction only.

First Edition: 2011

ISBN 978-93-5025-346-5

Typeset at JPBMP typesetting unit

Printed at Rajkamal Electric Press, Plot No. 2, Phase-IV, Kundli, Haryana. 
Dedicated to My Parents and wife 



\section{CONTRIBUTORS}

\section{Wilfred C G Peh}

MBBS (Singapore), MHSM (Sydney), MD (Hong Kong), DMRD (London), FRCP (Glasgow), FRCP (Edinburgh), FRCR (UK)

Advisor and Immediate Past Editor,

Singapore Medical Journal

Clinical Professor, National University of Singapore

Senior Consultant and Head

Department of Diagnostic Radiology

Khoo Teck Puat Hospital, Singapore

\section{Kwan-Hoong $\mathbf{N g}$}

BSc (Aberdeen), PhD (Malaya), MIPEM (UK), FInstP (UK), DABMP (USA)

Editor, Biomedical Imaging and Interventional

Journal

Senior Professor, Department of Biomedical Imaging

University of Malaya

Malaysia

\section{Fatema Jawad}

MBBS (Dow Medical College, Karachi) MCPS (College and Physicians and Surgeons, Pakistan) FRCP (Edinburgh)

Editor-in-Chief

Journal of Pakistan Medical Association

PMA House, Aga Khan 111 Road

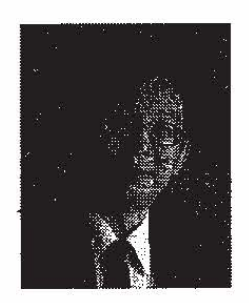

Karachi, Pakistan

\section{Prakash Mungli MBBS MD}

Associate Professor in Biochemistry and Genetics

St Matthew's University, School of Medicine

Grand Cayman, Cayman Islands, BWI

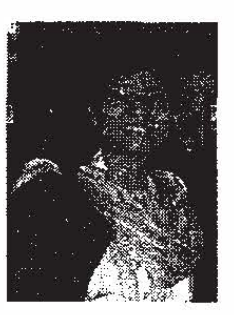

Nirmala Rao BDS MDS

Dean

Professor

Department of Oral and Maxillofacial Pathology

Manipal College of Dental Sciences

Manipal, Karnataka, India
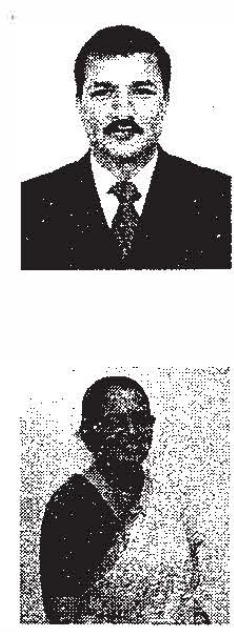
viii Publish and Flourish: A Practical Guide for Effective Scientific Writing

Keerthilatha M Pai BDS MDS

Associate Dean

Professor and Head

Department of Oral Medicine and Radiology

Manipal College of Dental Sciences

Manipal, Karnataka, India

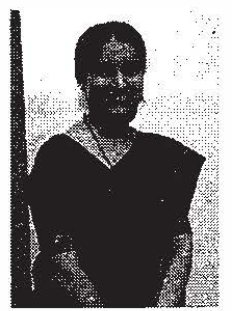

KL Bairy MBBS MD PhD

Professor and Head

Department of Pharmacology

KMC Manipal

Director, Manipal Center for Clinical Research

Manipal, Karnataka, India

Shailesh Lele BDS MDS

Principal, Professor and Head

Department of Oral Medicine and Radiology

Sinhagad Dental College and Hospital

Pune, Maharashtra, India



Ranganathan Kannan BDS MDS MS (Ohio) PhD

Department of Oral and Maxillofacial Pathology

Ragas Dental College and Hospital

Chennai, Tamil Nadu, India

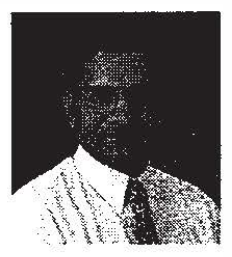

Shreemathi S Mayya MSc MEd PhD

Associate Professor

University Department of Statistics

Manipal University,

Manipal, Karnataka, India

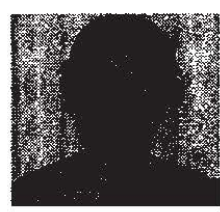

Kandaswamy Deivanayagam BDS MDS

Professor and Head

Department of Conservative Dentistry and Endodontics

Meenakshi Dental College

Chennai, Tamil Nadu, India

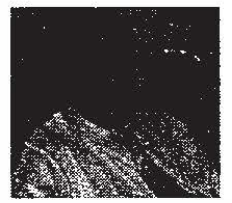


Vijay Prakash Mathur BDs MDS

Assistant Professor

Department of Pedodontics and Preventive Dentistry

Center for Dental Education and Research

All India Institute of Medical Sciences

Ansari Nagar

New Delhi, India

Sumanth Prasad BDS MDS

Professor and Head

Department of Public Health Dentistry

ITS, Dental Center for Dental Sciences and

Research Muradnagar

Delhi, Meerut Road

Ghaziabad, Uttar Pradesh, India

Vidya KM BDS MDS

Senior lecturer

Department of Oral and Maxillofacial Pathology

Ragas Dental College and Hospital

Chennai, Tamil Nadu, India

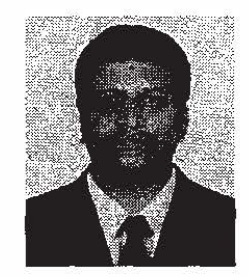

Ashutosh Sharma BDS MDS

Consultant, Pediatric and Special Care Dentistry

Shams Moopen Dental Practice (DM Healthcare)

Dubai Marina

Dubai (UAE)

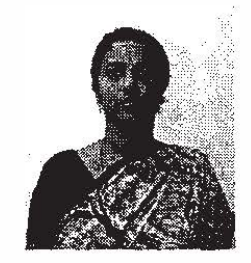

Amar A Sholapurkar BDS MDS FAGE

Reader

Department of Oral Medicine and Radiology,

Manipal College of Dental Sciences

Manipal, Karnataka, India


I am delighted that Dr Amar Sholapurkar has embarked on this venture of bringing out such a much-needed book on 'Publish and Flourish: A Practical Guide for Effective Scientific Writing.' Any scientific work must be published and therein lie the pitfalls. I must congratulate him for the timeliness and the content. At this time when, scientific writing is becoming even more daunting with

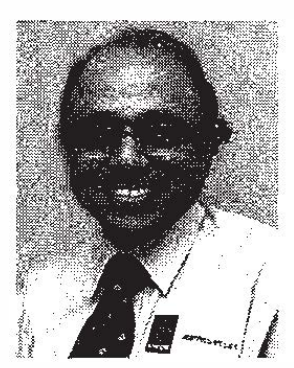
the plethora of scientific journals, it is fitting that this book addresses some very foundational issues pertaining to scientific writing. The comprehensive coverage of topics in the book will provide all the necessary information for the fledgling scientific writers as well as to the more experienced ones. It is not always easy to get all the information pertaining to scientific writing in one place; this book is indeed a laudable effort in that direction. The contributors, with their extensive experience in scientific writing, have lucidly articulated their viewpoints on very many subtle issues associated with writing science. This book is a must-read for anybody who takes scientific writing seriously, systematically and scientifically. Let this book make scientific writing more enjoyable and worthwhile.

Prof K Ramnarayan

Vice-Chancellor Manipal University Manipal, Karnataka, India 

I am extremely glad to pen down a few words about this conscientiously written book titled 'Publish and Flourish: A Practical Guide for Effective Scientific Writing' which is a unique and pioneering attempt by a very young and dynamic faculty, Dr Amar Sholapurkar.

A critical aspect of the scientific process is the

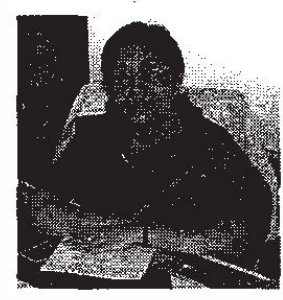
reporting of new results in scientific journals in order to disseminate that information to the larger community of scientists. $C$ smmunication of one's results contributes to the pool of knowledge within our discipline (and others) and very often provide information that helps others interpret their own experimental results. An objective of organizing a scientific research paper is to allow people to read one's work selectively for which excellent writing skills are essential for effective communication.

This book is indeed comprehensive with well-compiled chapters which are formatted in an easy sequence. The author has made a sincere and systemic approach to present succinct panorama of various aspects on how to write scientific paper to fulfill the long-term need of a concise book in this field. I am sure that owing to its simple language and indepth explanation of every section, this book undeniably be used by all those students and faculty members who are craving to mark a niche in academics.

On behalf of all the students and fraternity of MCODS, Manipal, I take this opportunity to congratulate Amar A Sholapurkar for this commendable work and hope that we would have greater learning from all the efforts that have gone into making of this first edition.

Prof Shobha Tandon Former Dean MCODS, Manipal Karnataka, India 

One cannot become a good cook just by watching someone else prepare a succulent meal. The modish phrase "hands on experience" describes the position very well: everyone needs direct practical involvement to become accomplished at anything. That includes the skill of writing a scientific paper. I have done my best to make this guide accessible to the students (both undergraduates and postgraduates) and faculty members of almost all the disciplines of health sciences. I wanted to help them to commit themselves to write and communicate effectively with their fellow colleagues. The book is designed specifically keeping in mind with all the core skills you need to make your mark as a high performing and an effective scientific writer. The book provides essential pointers for the beginners who are not well versed in writing a scientific paper. This compact, easy-to-use guide is a concise, yet comprehensive reference available for today's writers that guides through the step-bystep method of preparation of an article and getting it published in a good biomedical journal. It offers practical advise, clear definitions, and helpful explanations in a clear and readable style. The principles applied are applicable to all the disciplines of health sciences. This book gives clear practical advises, illustrated with examples on how to write an original research paper, a review article, case report and letter to editor.

I hope that the contents of the manual would be of value to all the scientific writers, the response be overwhelmingly positive and be most widely adopted in the nation. On the other hand, I want you to enjoy while reading the material and also attempt to write a good scientific paper which would be acceptable in an international indexed journal with high impact factor. I hope that, this book would help any trainee scientist to improve his/her skills in writing a paper and enjoy in doing so.

Dear Readers-you can now bring up your skills and give your career prospects a boost by referring 'Publish and Flourish: A Practical Guide for Effective Scientific Writing.' I should welcome feedback on the usefulness and practicality of this first edition. Thanking you all.

Amar A Sholapurkar 



\section{ACKNOWLEDGMENTS}

No book of value is written alone. Countless people helped me with this book - those who taught me and those whom I have taught. I would be adding many pages to this book if I have to name everyone to whom I am indebted. As I began to get established in my career, I quickly realized that I need to focus my mind in helping the beginners to write a scientific paper which would be publishable in good biomedical journal. My very special word of thanks to my wife who helped me initiate and focus on this problem. I would like to dedicate this edition to my parents (for their unfailing patience, belief in my abilities, constant encouragement to rise in life and who have not only- stood by me but have always showered me with good wishes and blessings) and my wife (for her love, patience, and sacrificing time with me while the book was being written).

I owe an enormous debt to all the dynamic contributors for their valuable contributions. For all their many contributions, I would like to thank-Professor Wilfred CG Peh, Professor Kwan-Hoong Ng, Professor Fatema Jawad, Dr Prakash Mungli, Dr Nirmala Rao, Dr Keerthilatha M Pai, Dr KL Bairy, Dr Shailesh Lele, Dr Ranganathan Kannan, Dr Shreemathi S Mayya, Dr Kandaswamy Deivanayagam, Dr Vijay Prakash Mathur, Dr Sumanth Prasad, Dr Vidya KM and Dr Ashutosh Sharma. My special thanks to Professor Teo Eng Kiong, Editor, Singapore Medical Journal for permitting me to reproduce the materials from the articles published in Singapore Medical Journal. I would also like to thank Suzanne Paris (Rights and Permissions Coordinator, ABC-CLIO Press Santa Barbara, Califomia, USA), Cynthia Mulrow (Senior Deputy Editor, Annals of Internal Medicine) and Dr Sivapathasundaram (Editor of Indian Journal of Dental Research) for permitting me to reproduce the materials in the book.

Closer to home, I would specially thank Professor Ramnarayan for his support, encouragement, and writing the foreword for this book. I am grateful to Professor Shobha Tandon, Dean, MCODS, Manipal for writing the foreword and for being a constant source of inspiration. I wish to express my sincere gratitude to my esteemed teacher DrKeerthilatha M Pai, Associate Dean, Professor and Head, Department of Oral Medicine and Radiology, MCODS, Manipal for her concise and concrete suggestions as well as goodwill offered by her. I feel fortunate in having access to the resources of the Manipal University. 
xviii Publish and Flourish: A Practical Guide for Effective Scientific Writing

I extend my heartful thanks to Dr Vivekanand Kattimani (Department of Oral and Maxillofacial Surgery, Sibar Institute of Dental Sciences, Takkelapadu, Guntur) for his constant support and innovative ideas. My sincere thanks to Dr Suhas S, Professor, Department of Oral Medicine and Radiology, Siddharatha Dental College, Agalkote, Tumkur for his wonderful suggestions, honest and wise advises. I specially thank Dr Shailesh Lele, Principal, Sinhagad Dental College and Hospital, Pune for helping me in suggesting the title of the book. I would like to thank Jaypee Brothers Medical Publishers (P) Ltd, New Delhi, who helped me through the editorial process with considerable skill and caring.

Most of all, I would like to thank Almighty God for loving me so much, giving me strength and ability to achieve.

Thanking you all. 


\section{CONTENTS}

\section{SECTION 1: INTRODUCTION}

1. Introduction

- What is Scientific Writing? 3

- What is Scientific Paper? 3

- Why to Write a Paper? 4

\section{SECTION 2: PRELIMINARY CONSIDERATIONS IN} WRITING A SCIENTIFIC PAPER

2. Planning to Write a Paper 9

- What to Write and When? 9

- What Not to Write? 10

- Where to Submit a Paper? 10

3. Deciding on Authorship (Who Should be the Authors?) 14

- The Dont's of Deciding an Author 15

- Number of Authors 15

- Order of Authors 15

- How to List the Names, Qualification and Address? 16

- Ghost Authors 16

4. Preparing to Write a Paper 18

- Determining the Journals Requirements 18

- Composing the Working Title and Abstract 18

- Organizing the Paper [Master Plan] 19

- Collecting the Material 19

- Designing the Tables and Illustrations 19

- Copyright 19

\section{SECTION 3: WRITING AN ORIGINAL RESEARCH PAPER}

5. Writing the First Draft-Preliminary Considerations 25

- Things to Remember While you Write the First Draft 25

6. Preparing the Title 27

- How Should be a Good Title? 27

7. Preparing the Abstract 30

- Features of Abstract 30

- What is Structured Abstract and Unstructured Abstract? 31

8. Writing the Keywords 34 
9. Writing the Introduction 36

- Tips to Write an Introduction 36

10. Describing How to Write the Material and Methods 39

- Materials 40

- Methods 41

- Statistical Evaluation $\quad 41$

- Common Problems 42

11. Interpretation and Use of Statistics in Publication 48

- Tests for Categorical Data 49

- Tests for Quantitative (Continuous)
Data and Symmetric Distributions (Parametric Tests)

- Tests for Ordinal Data or Skewed Distributions (Nonparametric Tests) 56

- General Guidelines for Reporting Statistics 58

12. Preparing Effective Tables 61

- Designing the Tables 61

- Requirements/Indications for Using a Table 65

13. Preparing Effective Illustrations

(Graphs, Photographs, Photomicrographs) 67

- Preparation of Graphs 67

- Preparing Effective Photographs 69

14. Writing the Results 72

- Presenting the Results 72

- Use of Tables and Illustrations to Present Results 73

- Organizing the Results $\quad 74$

- Common Problems 74

15. How to Write the Discussion and Conclusion? 79

- Components of the Discussion 79

- Common Problems 80

16. Quoting the References 84

- Definition of a Bibliographical Reference 84

- Why Cite References? 85

- What is its Purpose? 85

- References: Much ADO About Nothing 85

- What Kind of Information Needs a Reference? 85

- Components to Citing References 85

- Which Sources can be Used for Referencing? 85

- Some Tips for Referencing 85

- Two Major Systems of Citing References 86

- Vancouver System 86

- Which System Should I Choose? 90

17. Writing the Acknowledgments 92

- Categories of Acknowledgment 92 
18. Submitting the Manuscript 95

- Cover Letter 96

- Important Check Points Before Submitting a Manuscript 97

- General Tips 100

- Mode of Submission of a Manuscript 101

SECTION 4: SYSTEMATIC REVIEW, META-ANALYSIS AND WRITING A NON-RESEARCH PAPER

19. Understanding Systematic Review and Meta-Analysis 105

- Systematic Review 106

- Meta-Analysis 119

20. How to Write an Invited Review Paper? 123

- Structure and Contents of an Invited Review 124

21. How to Write a Case Report? 129

- What is a Case Report? 129

- The First Step to be Taken 130

- Writing the Case 130

22. How to Write a Letter to the Editor? 133

- What is a Letter to the Editor? 133

- Who Should Write a Letter to the Editor? 133

- Why are Letters Important? 133

- What Should be Written in Letter to Editor? 134

- How to Write a Letter to the Editor? 134

\section{SECTION 5: MISCELLANEOUS}

23. Managing Scientific Literature: Editor's Note 137

- Dealing with Submissions 138

- Dealing with Reviewers 139

- Dealing with Authors 140

- Dealing with Printers and Publishers 141

24. How to Deal with Editors? 142

- Editorial Decision 142

- The Entire Process of Publishing a Paper in a Journal 147

25. Ethical Considerations in Good Publication Practice 150

- Ethics and Medical Research 150

- Guidelines on Good Publication Practice 153

- Conflicts of Interest in Medical Research 156

- Web Resources on Publication and Research Ethics 158

- Research Ethics 158

- Publication Ethics 159

26. Understanding Informed Consent 162

- The Meaning and Need for Informed Consent 162

- Ethical Principles of Informed Consent 163 
xxii Publish and Flourish: A Practical Guide for Effective Scientific Writing

- Informed Consent Measures 164

- The Clinical Trial Volunteer's Bill of Rights 166

- Difficulties in Obtaining Informed Consent 167

- Situations Where Consent may not be Obtained 167

- Suggestions for Writing Informed Consent Documents 168

- The Use of Headings to Format Informed Consent Documents 169

- Conclusion 170

27. English Language, Abbreviations and Acronyms in Medical Writing $\quad 171$

- English Language 171

- Abbreviation 172

- The Rise of the Acronym 173

28. Abbreviations for Units of Measurements 175

- Units of Time 175

- Units of $\mathrm{pH} \quad 175$

- Units of Concentration 176

- Units of Temperature 176

- Units of Liquid Volumes 176

- Metric Equivalents 177

- English Equivalents 177

- Units of Volume 177

- Units of Mass 178

29. Understanding Journal Impact Factor and Citation Index 179

- Historical Background 179

- Method of Creating Journal Citation Report 180

- Some Definitions 180

- End Note 183

30. Frequently Asked Questions 185

\section{Appendices}

Appendix-1 Selected Journal Title Word Abbreviations 191

Appendix - 2 Abbreviations that may be Used Without

Definition in Table 194

Appendix - 3 Common Errors in Style and in Spelling 195

Appendix - 4 Words and Expressions to Avoid 199

Appendix-5 Prefix and Abbreviations for SI Units 203

Appendix-6 Accepted Abbreviations and Symbols 203

Terminologies 207

Index 213 


\section{Section 1 Introduction}





\section{Introduction}

Amar A Sholapurkar

\section{INTRODUCTION}

Authors are interested in various aspects of medicine, including areas like the dentistry, allied health professions, occupational therapy, nursing, veterinary medicine, pharmacy, etc. All these areas need good writers to communicate their work effectively! The competition for tenure-track faculty positions in academia puts increasing pressure on scholars to publish new work frequently. Faculty members who focus on non-publishing-related activities (such as instructing undergraduates or postgraduates) or who publish too infrequently may find themselves out of contention for available tenure-track positions.

\section{WHAT IS SCIENTIFIC WRITING?}

If the reader is to grasp what the writer means, the writer must understand what the reader needs.

George Gopen, Judith Swan.

Humans have been able to communicate since considerable number of years, however, scientific communication is relatively rare. Science is often hard to read and write as well. The quality, clarity, understanding, communication and language of writing are the key characteristic of scientific writing which is of large and practical significance. Improving the quality of writing improves the quality of thought. Scientific writing is the basis of going to institutions, universities, libraries to gain information and knowledge and present it in a concise manner.

\section{WHAT IS SCIENTIFIC PAPER?}

The modern form of scientific publishing began in the 17th century when gentlemen decided that it would be a good idea to share the results of their endeavors among their peers, for assessment, confirmation and 


\section{Publish and Flourish: A Practical Guide for Effective Scientific Writing}

debate. It is very important that students, authors, researchers, editors and other concerned individuals understand what a scientific paper is. A scientific paper is a written and published report describing original research results. A well written scientific paper explains the researcher's motivation for doing/conducting a study, the study design and execution, and its eventual results. Scientific papers are written in a style that is exceedingly clear and concise. The main purpose is to inform the readers and document the approach they used to investigate that issue. Scientific paper helps to assess the observation, to repeat the experiments/study and evaluate the intellectual processes. A scientific paper usually has clear purpose, be organized systematically and target specific readers.

Scientific paper should meet the criterion of a valid publication and it should be represented clearly in component parts. It should be particularly documented in a prescribed format, i.e. IMRAD [Introduction, Methods, Results and Discussion]. The heading "Materials and Methods" is more preferred than simply "Methods". There have been different systems of organizations that were preferred by some journals. In this variation, methods appear last rather than second where we can call this as IRDAM. Whether one is writing an article about Medicine, Dentistry, Nursing, Pharmacy, etc. the IMRAD format is most preferred choice.

\section{WHY TO WRITE A PAPER?}

If I ask you a question 'why we must write' most of us would answer "to communicate", some say for "name", "fame" and others say for "promotion purpose" in their institutes and the list goes on...... Yes, it is true that "communication" is very important. We write as it makes us remember, think, plan and express our thoughts. By writing we can communicate with people whom we have never met where they can judge us in the only way which is by our writing.

Preparing publishable manuscripts is an important aspect of professional life in research especially for those in academics. Scientific writing skills can be developed through long process of training and experience. Research work is incomplete unless the results are disseminated to a wider community. It is always good to make the results accessible. It gives the scientific community a good chance to find out about your work. It improves your writing skills in the sense that you will attract useful comments that you may have not thought of, which will eventually improve your future work. It is a way of paying back 
those who fund you. It gets you and your work well recognized in wider scientific community which is good for your career and institution. If you have a good track record of publications it becomes easier to attract funds. Publications may also lead you to be invited to peer review the work of others. You may be invited to join the editorial board of various top journals. Writing also helps you to share your discovery, your experiences with the rest of the world. If you are a junior faculty member then writing papers is fundamental to your profession and crucial to your promotion.

Research is an important tool in the discovery of new events and understanding of new phenomena. It is true that carrying a research is a challenging experience and also publishing the results is more a daunting exercise. However, carrying out research is incomplete if the results are not published. In this contest, I would like to describe a naturalist who is of no use if he is only an observer and never a writer. People who are inquisitive find the dynamic and rapidly growing field of biomedical writing that is very satisfying.

Scientific writing is an activity which all of us need to enjoy. The goal of scientific research is publications. It is a fact that authors become known by their publications. An original research, case report, review, etc. no matter how fantastic and well it is, is definitely incomplete until it is published. It is perhaps of great concern and importance that a "researcher" must provide a written document showing what was done and what was learnt from it. In short, I would like to call it as reproducibility. A good author will not only "do" science but also "write" which can be read by the widest possible audience.

There are three categories of people. First, are those who know the importance of writing, take trouble in doing so and will achieve in publishing their work in scientific journals. Others, who are satisfied with their writing, write without thinking about the possibility of improvement. Well the third categories are those who know that they write badly but do not worry about this and remain unsuccessful and remain unaware of their shortcoming.

Nowadays scientific publishing in peer-reviewed international indexed journals is not easy. Most of the articles (up to 30-50\%) get rejected due to various reasons. Writing a paper for a scientific journal is like trying to start an old car. An inexperienced driver will obviously have problems in starting and driving a car. It is a well known fact that "difficulties in your life do not come to destroy you, but to help you realize your hidden potential" and it is my opinion that "let the 
difficulties know that you are difficult." This quote would be applicable in the same context where I am trying to point out the vital importance of writing a scientific paper where dedication and confidence are two qualities which you need to develop. Yes, dear young readers, you should be aware at this instance that how important, it is to get your work published in good journals to achieve the highest goals in your career.

In this book, I have tried to help the beginners through this painful period by suggesting how they can get their work published in a good scientific journal. The purpose of this book is to help undergraduates, postgraduates and the faculty of Dental Sciences, Medical Sciences, allied health professions, occupational therapy, nursing, veterinary medicine and pharmacy to prepare manuscripts that may be accepted for publication in high impact factor journals. 